\title{
The relevancy of law enforcement toward water quality in Kali Buntung's downstream area
}

\author{
Lisa Elizabeth Gunawan* and Irwan Bagyo Santoso \\ Department of Environmental Engineering, Faculty of Civil, Environment and Geo Engineering, \\ Institut Teknologi Sepuluh Nopember, Indonesia
}

\begin{abstract}
Kali Buntung actually is a man-made afvoer river. However, due to city development, the location now become a strategic asset for Sidoarjo Region. Due to that reason, this river experience external forces such as rapid land conversion, social, law enforcement, upstream quality, rainfall and surrounding businesses that make the rivers' burden much heavier. This paper aims to investigate the external forces matters and the calculating the impact of those external forces towards the water quality in Kali Buntung's downstream area. Using Structural Equation Model (SEM) as the basis to produce such intended result, the indicator data will be processed using SMART PLS statistic software. The result of this research was: (1) the upstream water quality is very significant with the water quality in downstream. (2) rainfall have a significant effect toward upstream water's revitalization process along the way the water flows toward the downstream. (3) social and business aspects have significant influence to the water quality in downstream. (4) law enforcement has positive impact on downstream's water quality, even surpass either the rainfall or business factors. (5) the law enforcement to businesses may reward greater impact than to the common inhabitant surrounding. (6) since land conversion is inevitable, law enforcement might be the only way to keep enjoying the favorable impact of business capability and agriculture field to reduce the pollutant in Kali Buntung's downstream.
\end{abstract}

\section{Introduction}

Basically, water bodies, to be specific in this paper, rivers, has their own mechanism to improve their own conditions. Therefore, when it comes to water bodies condition's improvement, in general will be 2 (two) major aspects play the role which are the internal and the external. In internal case, water bodies have so-called "self-purification" mechanism to heal themselves ${ }^{[1]}$. In virgin area such as untouch forest, its actually enough for take care of themselves and their surroundings. However, not many rivers have this exclusivity. Some other rivers, which located in crowded cities, may not be able to do so since they are heavily impacted by the external forces. Those external forces make the rivers' burden much heavier so that it disables the rivers to collect themselves just the mother nature does. This paper aims to investigate the external forces matters and the calculating the impact of those external forces towards the water improvement conditions of "Kali Buntung" in Sidoarjo region in east java, Indonesia.

Kali Buntung actually is a man-made afvoer river. However, due to city development, the location now become a strategic asset for Sidoarjo Region. Nowadays, it serves as sewer, irrigation, fishpond and also residential area. It's an industrial sewer in upstream but also used for food production in the downstream. It's has a very crucial role as the bio-accumulator for the community surrounding. To be able to serve for those contradictive needs, it's supposed that Kali Buntung has a better quality at least, second grade class in Indonesian law. Hence, its necessary to handle this condition by managing the external forces correctly.

In this paper, the data will used both secondary data obtained from the government offices and primary data from on-field observation. The data includes both the quality and the quantity at Kali Buntung in Balungbendo as the beginning point and (6) Ketegan as the end point. Those will be compared to the impact of (1) rainfall, (2) technology aspect, (3) law aspect, (4) social aspect, and (5) land conversion aspect of surrounding in Kali Buntung area. Those will be process using Structural Equation Modelling Partial Least Square to analyse which aspect matters the most for improving kaliBuntung water condition's.

Structural Equation Model (SEM) is a cause and effect analysis used to describe link between observation indicator link between observation variable (indicator variable) and variable that cannot be measured directly (latent variable) $^{[2]}$. It application's is broad and possible to be further explored. In Putranto and Santoso (2018) it used for choose among factors for drainage system solution. While, in this research is, SEM is used to analyze the effect and the significancy of those aforementioned 6 aspects. By having the analysis, the writer may come out with effective suggestions for the

\footnotetext{
* Corresponding author: lisaegunawan@gmail.com, irwan080565@gmail.com
} 
best way to improve kali-Buntung downstream water condition's. Both researches are looking for the solution for non-direct measured variable but different in the object. Within the social discussion, the latent variables which rarely being seen physically are important factors in actual. Sometimes, those even more than the countable physical one. In the other hand, environment in urban area sit in social shade, thus, any insight from this side of perspective may bring new horizon. This research offered a solution for water quality in Kali Buntung area, in future, it also possible to be a valuable study for other rivers with the same case in Indonesia.

\section{Materials and methods}

\subsection{Independent variables}

A set of observed variables ${ }^{[3]}$ that may be valued, each act as indicators for a specific aspect mentioned above. Those variables derived from the existing condition in research location, furthermore, categorized in accordance to the applicable set of theories.

\subsection{Smart PLS studies}

Structural Equation Model (SEM) used for analyse the effect and the significant value ${ }^{[4]}$ of independent variables used in the model. Those calculation including the interaction between variable, the number of sample, and various considerations as well. Since the number or the samples are limited, not every SEM software can run this properly. SMART PLS software allows the SEM calculation even with sample as few as 30 samples only, compare with others' which require at least 200 samples to run properly.

\section{Result and discussion}

\subsection{Location}

This research is taking place in area surrounding Kali Buntung in Sidoarjo. The river is stretch less than 25 kilometre long. However, as every river, it may impact the surrounding area. In this case, the impact area is indicated by the red line in picture below.

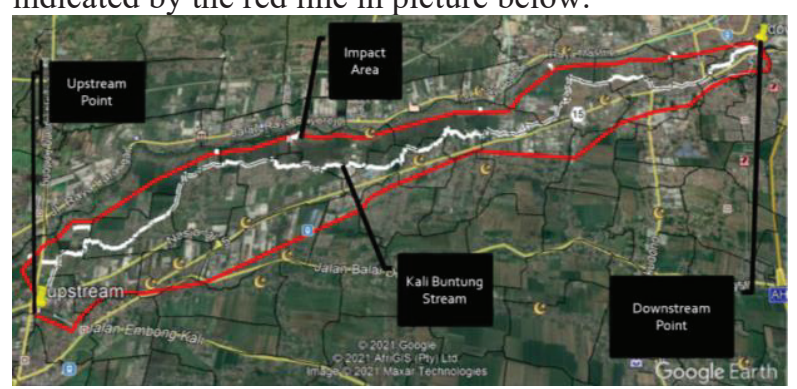

Fig.1. The map of research area

The upstream and the downstream point taken from local government's usual surveillance points as those points already have the data needed in the research.

\subsection{Model Concept}

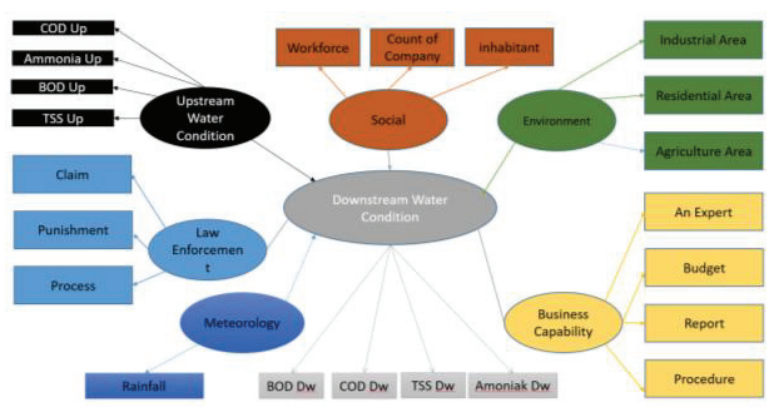

Fig. 2. The model concept mindmap

The model was derived from applicable theories collected by the writer. Later will be tested using the outer model step in SEM such as validity test, reliability test and multicollinearity test. Once passed, it will be eligible for further process in inner SEM model.

\section{Output of structural equation modelling analysis}

Even though the aimed end result (dependent variable) is only 1, which are the water quality of the Kali Buntung Downstream, the model produces 2 types of output in 7 steps. In usual case, this relation assumed as linear model sampling, but to do so it is required large amount of sampling. As mentioned in previous section, the sampling in this research is mainly divided by historical timeline, using SMART PLS, it allows both relatively small amount of data and non-linear sampling because it will eventually further process using bootstrapping method.

Bootstrapping process allows resampling process that may solve the data abnormality. Refer to 22 observed variables in total, and the aimed accuracy level of $80 \%$, the value of T-Table is 1.316 .

\subsection{Handed Model}

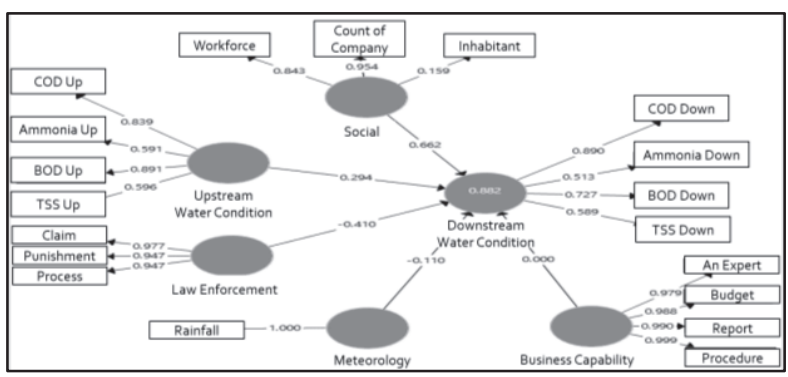

Fig.3. The Outer Model: Upstream-Downstream-Rainfall Social - Business - Law Enforcement

As the business and rainfall, law enforcement also has a favorable impact toward pollutant reduction in downstream area. Even more, with the presence of law enforcement, it able to shift the business capability and rainfall place as the most impactful factor among the others which shown by the number of law enforcement 
(-0.410) compare with rainfall $(-0.110)$ and plunge business capability into zero impact. Not to mention, reduce the unfavorable impact of social and upstream water in adding the downstream pollutant.

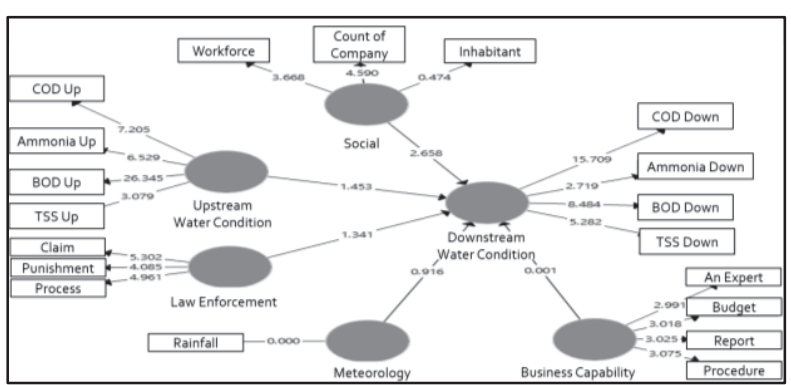

Fig.4. The Bootsrapping Model: Upstream-DownstreamRainfall - Social - Business - Law Enforcement

In addition, law enforcement even with the competition with the other factor, still can counted as a significant factor $(1.341>1.316)$ along with the Social $(2.658>1.316)$ and Upstream $(1.453>1.316)$ afterward. It means that, in this research, this factor does a powerful tools for revitalizing Kali Buntung downstream water quality. Only one out of those variables within those three significant factors proves insignificant, which is the civil population surrounding. It means that actually, business has more significancy in affecting the downstream water quality.

\subsection{The End Game: 5-Handed Model}

From the entire aspects observed, only one aspect proves insignificant, which is the land conversion aspect, eventhough in actual, green area is very good for the water quality. Moreover, since law enforcement, at the end, has the highest contribution and also proved significant, it even able to surpass business and rainfall as the most impacting factor. Suppose that this aspect is favorable control tools for water quality in downstream.

In addition, law enforcement actually a very interesting factor to explore further. It supposes can also direct the land and business aspect through government permit and regulation. Business shall bound to the environment permit as well as land to the land permit.

\section{Suggestion}

Even though some aspects in inner model do not look promising, but once it being breakdown again, they actually did it in their own way. Instead, they do impact the upstream water quality significantly, prove by their substantial amount of outer value. When it talks about the downstream water quality, it is really closely related to the upstream water quality. In wholistic river principle, garbage in garbage out really does matter. It is impossible to have good downstream water quality without good upstream quality either.

Since the land conversion and city development is inevitable factor in most civilization case, there is no way to keep the amount of agriculture field in promising area even though it is the best way to keep the water quality. It is true that meteorology has a significant effect too, but still, in accordance to the figure above, it has the lesser effect compare with law enforcement. Moreover, rainfall is complicated factor to be played since it also can trigger the flood and draught disaster. Therefore, the least optional effort is by controlling business institution, social population and land usage throughout the enforcement of the law. And it can only be done through law enforcement. Furthermore, the law enforcement to businesses may be an agile tool to embrace the other factors too. it can also direct the land and business aspect through government permit and regulation. As the business shall bound to the environment permit as well as land to the land permit.

\section{Conclusion}

This research aims to determine the effect and the significant indicators from land conversion, social, law enforcement, business and meteorology as well as give suggestion about what to do to keep the water quality of prominent Kali Buntung downstream area. The analysis resulted, that the 5 handed model works best.

The model suggests that social, law enforcement and upstream water quality is very significant for the downstream water quality. But ever since, wholistically river flows from the upstream to the downstream, the control in upstream will lead to the better downstream. Especially when the upstream is heavily impacted by the social and business which runs by the population, controlling the population through law enforcement may be the only way to save the water quality condition. It not also applicable in Kali Buntung case, but suppose the same conduct applies to other numerous amounts of similar case in Indonesia.

\section{Reference}

1. S. Tian, Z. Wang, \& H. Shang, Study on the Self-purification of Juma River (2011)

2. T.A. Brown, Confirmatory factor analysis for applied research. The Guilford Press (2006)

3. J.C. Putranto. \& I.B Santoso, Water Inundation Control Modeling for Greges Drainage System in Surabaya, Indonesia (2018)

4. D.F. Wicaksono, B. Rahadi, L.D. Susanawati, The Evaluation of Waste Water Pollution of Paper Factory in Sungai Klinter Kabupaten Nganjuk(2013)

5. A.K. Novitasari, Analysis on Pollution Sources at Kali Surabaya(2015)

6. M.A.A. Latif, M.S Pallu, J. Patanduk, The Study of Water Quantity and Quality in Sungai Tallo for Water Source (2012) 